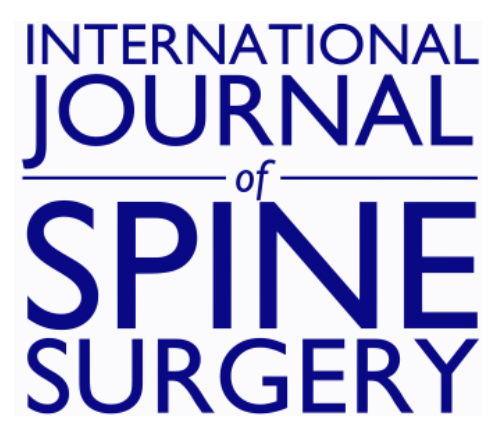

\title{
Five and Ten Year Follow-up on Intradiscal Ozone Injection for Disc Herniation
}

Josip Buric, Luca Rigobello and David Hooper

Int J Spine Surg 2014, 8 ()

doi: https://doi.org/10.14444/1017

http://ijssurgery.com/content/8/17

This information is current as of April 26, 2023.

Email Alerts Receive free email-alerts when new articles cite this article. Sign up at:

http://ijssurgery.com/alerts 


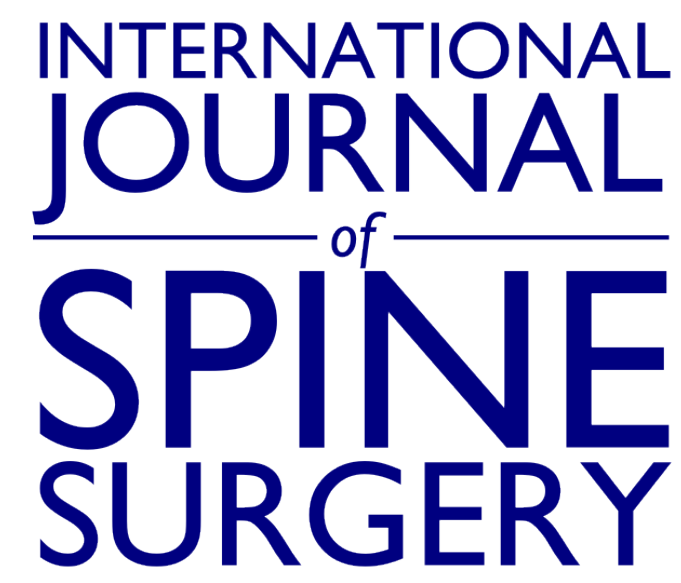

This article generously published free of charge by the International Society for the Advancement of Spine Surgery.

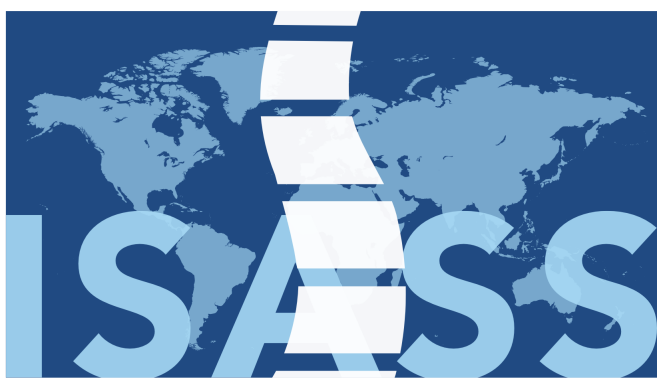

INTERNATIONAL SOCIETY for the ADVANCEMENT of SPINE SURGERY 


\title{
Five and Ten Year Follow-up on Intradiscal Ozone Injection for Disc Herniation
}

\author{
Josip Buric, $M D^{I}$, Luca Rigobello, $M D^{2}$, David Hooper $P h D^{3}$ \\ ${ }^{1}$ Villa Torri Hospital, Bologna, Italy ${ }^{2}$ Department for Neurosurgery University of Padua, Padova, \\ Italy ${ }^{3}$ Minimus Spine, Inc. Austin, TX
}

\section{Abstract}

\section{Background}

Disc herniation is the most common cause for spinal surgery and many clinicians employ epidural steroid injections with limited success. Intradiscal injection of ozone gas has been used as an alternative to epidural steroids and surgical discectomy. Early results are positive but long-term data are limited.

\section{Methods}

One hundred and eight patients with confirmed contiguous disc herniation were treated with intradiscal injection of ozone in 2002-2003. One-hundred seven patients were available for telephone follow-up at 5 years. Sixty patients were available for a similar telephone follow-up at ten years. Patients were asked to describe their clinical outcome since the injection. Surgical events were documented. MRI images were reviewed to assess the reduction in disc herniation at six months.

\section{Results}

MRI films demonstrated a consistent reduction in the size of the disc herniation. Seventynine percent of patients had a reduction in herniation volume and the average reduction was $56 \%$. There were 19 patients that ultimately had surgery and 12 of them occurred in the first six months after injection. One of these 12 was due to surgery at another level. Two surgeries involved an interspinous spacer indicated by stenosis or DDD. All other surgeries were discectomies. Of the patients that avoided surgery $82 \%$ were improved at 5 years and $88 \%$ were improved at 10 years. Other than subsequent surgeries, no spinerelated complications were experienced.

\section{Conclusions/Level of Evidence}

We conclude that ozone is safe and effective in approximately $75 \%$ of patients with disc herniation and the benefit is maintained through ten years. This is a retrospective review and randomized trials are needed. 


\section{Clinical Relevance}

Intradiscal ozone injection may enable patients to address their pain without multiple epidural injections and surgery. The benefit of ozone is durable and does not preclude future surgical options. The risk reward profile for this treatment is favorable.

\section{Introduction}

Disc herniation is the most common cause of lumboradicular pain and is the most frequent indication for spine surgery. The yearly incidence rate of disc herniation in the United States has been reported to be $1.7 \%{ }^{1}$ From $1990-1993,0.8 \%$ of the population of Washington State had first time surgery for disc herniation annually. ${ }^{2}$ The rate of reoperation is between $7-9 \%$ at 2 years ${ }^{3,4}$ and increases up to $10-25 \%$ at ten years postoperative. $^{5,6,7,8,9,10,11,12,13,14}$ Patients with extensive epidural scarring are three times or more likely to experience recurrent radiculopathy than those with less extensive epidural scarring. ${ }^{15,16,17}$

Conservative care should be exhausted prior to surgery. It is estimated that in 2007, there were over one million U.S. patients in conservative care for disc herniation and an additional 245,000 opting for surgery. In the Medicare population, the annual rate of epidural injections has been reported to be 2055 per 100,000 patients. ${ }^{18}$ Nine percent of those were for a diagnosis of "herniated disc" and 33\% were for "radiculopathy". Steroid injections have a transient effect and the average number of injections received by a patient was 2.5. Assuming a population of 300 million, approximately 222,000 U.S. patients are undergoing steroid injection each year specifically for disc herniation and an additional 813,000 for radiculopathy. Approximately $25 \%$ to $72 \%$ of patients having epidural steroid injections for disc herniation go on to surgery within two years. ${ }^{19,20,21}$

Intradiscal injection of ozone $\left(\mathrm{O}_{3}\right)$ gas was first proposed in the $1980 \mathrm{~s}$ as a treatment for disc herniation. Ozone is a tri-atomic form of oxygen that can be created through corona discharge or ultraviolet light. Ozone has a half-life of approximately 45 minutes at ambient conditions, reverting back to oxygen, and therefore must be produced on-site for immediate injection. Ozone is a strong oxidizer and its application to the nucleus results in cleaving of the proteoglycan molecules and neutralization of the negatively charged sulfate side chains. ${ }^{22}$ This likely reduces the disc's ability to retain water and results in a reduction of the herniation volume. ${ }^{23}$

Several animal studies involving spinal application of ozone have been reported in the literature. These include dose response studies in rabbits, ${ }^{24,25}$ an acute toxicity study in pigs, ${ }^{26}$ and a veterinary application to dogs presenting with parasthesia or paralysis due to disc herniation. ${ }^{27}$ These studies support that ozone has a dose-related response involving changes to the collagen fibrils and nucleus cells. Ozone had no toxic effect when injected into the epidural space of pigs. Canines treated with ozone demonstrated improved function that was maintained out to 18 months. 
Two animal studies have been published that investigated the effect of ozone on cytokines. ${ }^{28,29}$ A mouse model of rheumatoid arthritis was used to investigate the relationship between ozone exposure and cytokine production. Levels of TNF- $\alpha$, IL- 6 and IL-1B significantly decreased with ozone concentrations between 1 and $5 \%$, relative to controls. Another mouse model used a spared nerve root injury to demonstrate that a single subcutaneous injection of ozone was responsible for a reduced expression of inflammatory caspases and IL-1B in the orbitofrontal cortex, suggesting that ozone may have a positive effect on pain signaling.

Several clinical reports of the use of ozone to treat lumbar ${ }^{23,30,31,32,33,34,35,36,37,38,39}$ and cervical $^{40,41}$ disc herniations in humans have been presented in the literature. Two randomized blinded trials have been conducted to date: one comparing intradiscal ozone to steroids for radicular pain associated with disc herniation ${ }^{30}$ and the other comparing intramuscular injections of ozone to sham injection for back pain. ${ }^{42}$

Authors consistently report success rates between $65-80 \%$ and few complications. There are isolated case reports involving adverse events following intradiscal injection of ozone. These include a case of transient bilateral blindness following injection of a large volume of ozone to the disc without radiographic control, ${ }^{43}$ a nerve root injury associated with a pressure spike during the injection, ${ }^{44}$ a thunderclap headache attributed to puncture of the thecal sac, ${ }^{45}$ a severe case of discitis requiring revision surgery, ${ }^{46}$ and a fatal septicemia due to E. Coli infection. ${ }^{47}$ Two meta-analysis of intradiscal ozone have been published and both concluded that intradiscal ozone injection is both safe and effective in patients with disc herniation. ${ }^{48,49}$

This report is being written to update our unpublished data detailing our 5-year experience with ozone to include data out to 10 years. We have supplemented our initial clinical review and 5-year phone interviews with a similar phone interview conducted at 10 years.

\section{Methods}

\section{Demographics}

From January 2002 through January 2004108 patients (57 males/51 females, mean age $46.7 \pm 15.1$ years) were treated with percutaneous ozone chemonucleolysis. All patients suffered radicular leg pain and some reported additional back pain. The duration of symptoms was at least one month (mean $9.4 \pm 15.0$ months and median 4 months) and patients were non-responsive to conservative treatment modalities. Symptom duration was 3 months or more in $69 \%$. None of the patients submitted to the treatment presented motor palsy of Fisher $<4$. In all cases, MRI was used to confirm a protruded or extruded $\mathrm{disc} / \mathrm{s}$ between L2 and S1. There were 91 patients with single level involvement, 15 with 2 levels and 2 with three levels. Patients that presented with signs of motor palsy (Fisher $<4$ ), low back pain as the only symptom, sequestrated (free) disc fragments or other spinal pathologies such as tumours, lyses, fractures, severe stenosis and previous spinal surgeries, were not treated with ozone and are therefore not included in the study. All patients gave informed consent. 


\section{Procedure}

The procedure was performed in the operating room under moderate sedation. The patient was prepared by the anaesthesiologist with pharmacological sedation half an hour before the procedure and then brought to the operating room and positioned in lateral decubitus leaving the affected side upwards with the hips and knees flexed in the fetal position. The operating table was adjusted to assume an upwards convex shape, allowing the surgeon easier access to the disc. After standard antiseptic prepping and sterile draping, a Chibatype needle (18 G, $27 \mathrm{~cm}$ long) was introduced by the standard postero-lateral, extraarticular percutaneous approach. The side of approach corresponded to the side of maximal pain as described by the patient. This corresponded to the side of disc herniation as seen on the MR images in $97 \%$ of patients. The gas disperses throughout the disc and annular tears so the side of approach is not believed to be critical. All procedures were performed under fluoroscopic control. Antero-posterior and lateral imaging confirmed the position of the needle within the disc. The needle tip was situated centrally inside the nucleus pulposus.

The ozone-oxygen mixture was produced in real-time by a medical ozone generator (Ozonline E 80, Medica srl, Bologna Italy). The concentration of the gas mixture was approximately $40 \mu \mathrm{g} \mathrm{O}_{3} / \mathrm{ml} \mathrm{O}_{2}$ and a quantity ranging between 5 to $10 \mathrm{ml}$ were injected into each indicated level. Between the syringe and the needle, a bacteriological Millipore filter was positioned before infiltrating the gas mixture inside the disc space. The ozoneoxygen mixture was released inside the disc space at an approximate rate of $10 \mathrm{ml} / \mathrm{min}$. The gas mixture inside the disc space was visible on fluoroscopy. Gas was observed diffusing through the disc space and through the herniation. The patient was kept for overnight observation and discharged the next morning. Return to work was permitted 7 days after the procedure. The mean time to complete the procedure was approximately 15 minutes.

\section{Clinical Assessment}

Patient history, demographic and clinical data were collected from hospital records and a confidential computer database was maintained by the investigator. An independent assessor performed telephone interviews at 5 and 10 years after the procedure. At five years and ten years, the patients were asked:

- How do you feel with respect to the pre-operative clinical status: worse, unchanged, better, much better?

- Have you had any recurrences of the pain since the initial injection?

- Do you use pain killers [for that specific problem]: never, occasionally, frequently or daily? "For that specific problem" was added at the 10 year follow-up.

Fifty-two patients with single level involvement had an MRI at six months follow- up (range 3 to 8 months). Images were evaluated by independent neuroradiologists and compared to the preoperative images. The change in the herniation volume was recorded in axial and sagittal views. 


\section{Results}

Of the original cohort of 108 patients, 107 were evaluated at 5 years. Twenty-six of the patients could not be reached at ten years (mainly to phone number change) and another 3 had deceased for reasons unrelated to their spine surgery. Records were reviewed thoroughly at the 5-year follow-up and 19 patients required surgery. Seventeen of the 19 surgeries were discectomies and two were interspinous spacers. Twelve of the 19 operations occurred within the first six months. One discectomy was performed at 22 months due to a herniation at another level. There were two cases of monosegmental stenosis at 51 months and 61 months, respectively, that were treated with interspinous spacers. The timing of these operations is provided in Figure 1. Overall, there were 16 discectomies at the affected level in 108 patients at 5 years $(15 \%)$ plus two cases of DDD/ stenosis. The ten year phone interviews did not identify any additional surgeries in the patients we were able to contact.

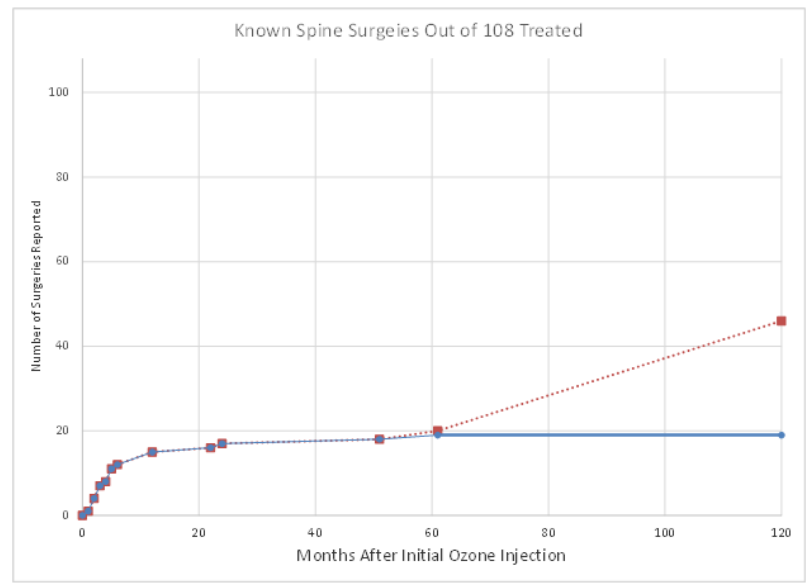

Fig. 1. Time course of operations following ozone treatment. The blue line represents actual responses from patients contacted. The red line indicates a worst-case scenario where all patients lost to follow-up went on to surgery.

A Mann-Whitney test was used to compare the duration of symptoms in patients undergoing surgery within 6 months to those that did not. There was no significant difference between these two groups ( $\mathrm{p}=0.98$ ). A Chi-square test was used to test if patients with single level involvement had a different operation rate than those with multilevel involvement. There was no significant difference between these groups $(\mathrm{p}=0.16)$.

In most patients, the size of the herniation was reduced at 6 months. See Figure 2. Of the 52 single level patients with MRI at 6 months, $42(81 \%)$ had a reduction of $50 \%$ or more. Nine patients (17\%) had no observable change in the herniation and three of those patients had surgery. In this series, there was no correlation between age and the reduction in herniation $\left(\mathrm{R}^{2}=0.04\right)$ 


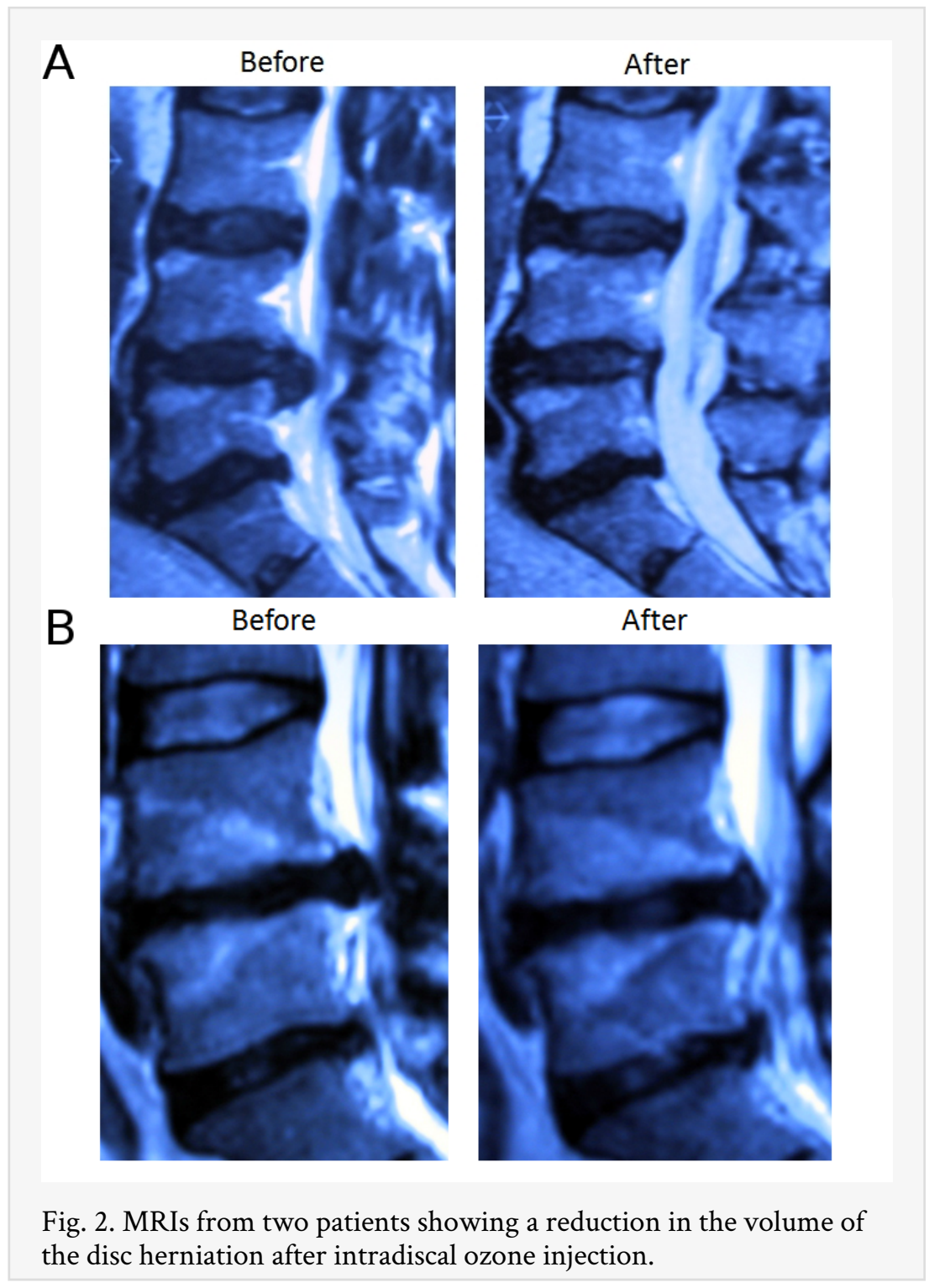

\section{Clinical Assessment at 5 years}

Of the 108 patients treated, $89(82 \%)$ did not require subsequent spine surgery at the index level. One patient was lost to follow-up. Seven of them had at least two ozone injections (7\%). Four of these second injections were done between 1 and 6 years after the initial injection. Of the 88 patients participating in the phone interview, $9(10 \%)$ reported a score of "Worse," 6 (7\%) were "equal," 32 (36\%) were "better," and 41 (47\%) were "much better."

\section{Clinical Assessment at 10 years}

At ten years, three of the original 108 patients had died since the five year follow-up. The 19 patients known to have had surgery based on the 5 year assessment were not contacted and their surgery result was carried forward. Sixty of the remaining 86 patients were reached for 10 year follow-up (70\%). Of these patients 2 (3\%) were "worse," 5 (8\%) were "the same," 27 (45\%) were "better," and 26 (43\%) were "much better." Forty-seven (47\%) of respondents reported that they "never" used pain medication for that specific problem, 
while 53\% reported using it "occasionally." No patients reported frequent or daily use of pain medication. Eighty-one (81\%) reported that they had never had an episode of the same or similar radiating pain recurrence since the initial injection.

With the exception of previously described spine surgeries, no other spine complications were observed. Specifically, there were no cases of discitis, septicemia, blindness, headache or cerebroprospinal fluid fistulae.

Table 1. Summary of Operations and Clinical Outcomes in patients not requiring surgery.

\begin{tabular}{|l|l|l|}
\hline & 5 years & 10 years \\
\hline Elected for Surgery & $18 \%$ & $18 \%$ \\
\hline Of those not electing for surgery... & & \\
\hline Much Better & $46.6 \%$ & $43.3 \%$ \\
\hline Better & $36.4 \%$ & $45.0 \%$ \\
\hline Same & $6.8 \%$ & $8.3 \%$ \\
\hline Worse & $10.2 \%$ & $3.3 \%$ \\
\hline
\end{tabular}

\section{Discussion}

Ozone chemonucleolysis for disc herniations has been performed for 20 years in countries such as Italy, India, Spain, Germany, Argentina, Korea and China. The authors are only aware of one other report of five-year follow-up following intradiscal injection of ozone. $^{36}$ That study reported on an aggregated 6,665 patients treated in Italy, Spain and Argentina. All patients had a disc herniation that was unresponsive to conservative care such as physical therapy and medication. These patients were treated with intradiscal ozone followed by four paravertebral injections rather than a single intradiscal injection, as in this report. These authors reported complete elimination of pain in $80 \%$, improvement in $12 \%$ and no improvement in $7 \%$.

To our knowledge, this is the first report of 10 year clinical outcomes following intradiscal ozone injection for lumbar disc herniation. This retrospective study suffers from two obvious drawbacks. The first is the lack of a control group and the second is the follow-up rate at 10 years. Due to the lack of a control group, the interpretation of efficacy data must be done with caution. Patients may have improved spontaneously without any treatment at all. However, this study does support the safety of this treatment. The follow-up rate at ten 10 years was $70 \%$. This also adversely impacts that determination of efficacy based on this study. However, given that this is the first report of 10 year data following ozone injection, we feel it is appropriate to present these data.

While $20 \%$ of these patients ultimately had surgery, the remainder were able to achieve a durable benefit with one, or perhaps two, intradiscal injections to the disc. Twelve of the 19 operations occurred within the first six months. These 12 are the cases which we consider the cases where ozone was not effective (11\%). Our opinion is that the remaining operations do not detract from this treatment because they were attributable to 
herniations developed at different levels or at a timing longer than 6 months. It is important to note that, these patients did not show long term evidence of DDD or disc collapse that would lead to spinal fusion surgery.

Recently, two randomized, blinded studies were performed using ozone in the treatment group. One is from Gallucci et al. ${ }^{30}$ that reported the results of a randomized, blinded study of 159 patients assigned to either ozone combined with steroids or steroids alone. The ozone concentration was $27 \mathrm{ug} / \mathrm{cc}$ and an average of $12 \mathrm{cc}$ was delivered, primarily to the disc. At two weeks the results between groups were equivalent, likely due to the shortterm effect of steroids and anesthetic. At three months, however, results began to diverge but were not significant. At six months $74 \%$ of the patients with ozone reached an ODI score of less than $20 \%$, whereas only $47 \%$ of the steroid-treated group reached this level of improvement. The other study is from Paoloni et al. ${ }^{42}$ that report on results of a multicenter, randomized, double-blinded study comparing intramuscular, paravertebral injections of ozone to simulated therapy. At 6 months follow-up, a statistically significant difference was observed between the two groups with the advantage for the ozone group of treatment.

Muto et al. ${ }^{34}$ reported on 2200 patients treated with intradiscal and foraminal ozone injections and followed for 18 months. A wide array of patients were treated including degenerative disc disease complicated with disc herniation, isolated herniation, failed back syndrome, calcified disc herniations and disc herniation associated with stenosis. Ozone injection was most effective in cases with single level disc herniations (64\% Excellent and 14\% Good or Fair) and the effectiveness decreased with disc degeneration (40\% Excellent, 39\% Good or Fair), calcified disc herniations (34\% Excellent, 19\% Good or Fair) and disc herniation with stenosis (25\% Excellent, 25\% Good or Fair). With all indications, maximum improvement was at 6 months and the results were stable to 18 months. If the placebo effect was solely responsible for the benefit then there would not be such a difference in the outcome based on the indication.

Given the lack of a control group in this study, the authors conducted a literature review on the outcome of epidural injections, discectomy, as well as the natural history. Several authors have attempted to compare conservative management to surgery. The results have been equivocal. ${ }^{3,4}$ There are significant challenges in designing randomized trials comparing non-surgical and surgical treatment for disc herniation, particularly cross-over between assigned groups. These studies indicated, per an intent-to-treat analysis, that there was no significant difference between conservative and surgical treatment after one to two years. The surgical treatment offered more immediate benefit but the results equalized over time. The amount of cross-over between assigned groups confirms that patients with more severe symptoms are apt to demand surgery while those with less severe symptoms are prone to delay surgery. Patients appear well suited to balance the risk and benefit of their treatment options. In our experience, patients responding to intradiscal ozone injection receive significant improvements within several weeks of the injection.

There have been a number of papers describing the long term results of discectomy. An early meta-analysis performed by Hoffman et al. reported that $65-85 \%$ of patients undergoing discectomy had complete relief of sciatica at one year. However, with time, an increasing percentage of patients received additional spine surgery. At ten years, 
approximately $10 \%$ of patients had received additional spine surgery. Loupasis et al. performed a long term follow-up through postal mail on 109 patients 7-20 years after discectomy. Twenty-eight percent of patients still complained of significant pain in the back or legs. Sixty-five percent were satisfied based on the Stauffer Coventry score. The reported reoperation rate was $7.3 \%$ and they occurred, on average, approximately 6 years after the index surgeries. Reoperations were attributed to reherniations, scar tissue and instability. Carragee reported 2 year results (average 4.9 years) of 149 patients receiving discectomy. There were reherniations in $11 \%$ of patients and $5 \%$ underwent reoperation. Asch reported outcomes of 212 patients that underwent microdiscectomy for lumbar disc herniation. At an average follow-up of two years, $11 \%$ percent of patients had a subsequent surgery, typically another discectomy, and $2 \%$ had a third lumbar surgery. Seventy-six percent of patients were satisfied at the final follow-up. Intradiscal ozone injection offers a comparable success rate to surgical discectomy without surgery. Our study found that only $18 \%$ of patients treated with ozone went on to surgery. Taking in account the loss to follow-up between 5 and 10 years, we considered also the worst-case scenario where all patients lost to follow- up required surgery (which is quite unlikely but possible). Under this worst case scenario, $43 \%$ of patients required surgery within 10 years. Even in this case, the results seem acceptable as compared to the results of other studies on natural history or other types of treatment of disc herniation at the lumbar level. The injection of ozone followed by an $18 \%$ (to $43 \%$ ) operation rate is preferred to an initial discectomy followed by a $10 \%$ reoperation rate.

Conservative care should be exhausted prior to surgery but options are few. Others have cited that patients receiving epidural spinal injections take an average of 2.5 injections $^{18}$ and between $25-72 \%$ go on to surgery within two years. ${ }^{19,20,21}$ The clinical benefit of steroid injection is limited to a transient improvement in leg pain. Our study demonstrated that just $18 \%$ of patients treated with ozone went on to surgery within five years and there were no reports of additional surgeries all the way out to ten years. At 10 years, this could possibly be as high as $43 \%$. Fifteen percent of patients had discectomy related to the disc treated with ozone while 3 percent had some other type of spine surgery. Approximately $90 \%$ of patients required only a single ozone injection and those that required a second injection were often years later. Of the patients that avoided surgery, $88-90 \%$ of patients were better at 5 and 10 years.

In contrast to steroid injections, the benefit of ozone is believed to be more durable because it affects the herniation. Lehnert performed an MRI analysis of disc volume in 283 patients with radiculopathy that were treated with intradiscal injection. ${ }^{23}$ Disc volumes were measured before and six months after injecting $3 \mathrm{ml}$ of gas to the disc and 7 $\mathrm{ml}$ of gas in the periganglionic space. The ozone concentration was $30 \mathrm{ug} / \mathrm{ml}$. The authors reported a statistically significant reduction in disc volume averaging $8 \%$ and the amount of reduction was inversely correlated with age. We observed that out of 53 randomly selected patients performing a control MRI after the treatment, 42 patients (79\%) showed regression of the herniation volume of approximately $56 \%$. All of these patients had a significant clinical improvement. Other authors have also reported that the disc herniation volume is not always correlated with clinical symptoms and that the persistence of herniation may not be correlated with the worsening of clinical status. ${ }^{50}$ Asymptomatic patients with positive CT scans for disc herniation are not a rare event. ${ }^{51}$ 
The biochemical component of the disc degeneration is an important source of pain that is coupled with nerve root compression. Recently, laboratory results showed that epidural application of autologous nucleus pulposus can induce pronounced morphological and functional changes in nerve roots due to an increase in endoneurial fluid pressure and a decrease of blood flow in the dorsal root ganglia with resulting concomitant increase in its excitability and mechanical hypersensitivity. ${ }^{52,53}$ Phospholipase A2, tumor necrosis factor $\alpha$, metalloproteinases and some other substances were found in great quantities in the degenerated nucleus pulposus. These were found able to cause nerve root injury by partial demyelination that increases nerve root mechano-sensitivity making the nerve root more susceptible to mechanical pressure. The mechanical factor seems then to be able to trigger hyper excitability and the ectopic nerve impulses in primary afferent axons that cause neuropathic paresthesia and pain. ${ }^{54,55}$

Basic science studies on ozone activity, conducted in several University centers in Italy, found that the mixture of ozone and oxygen had a potent, dose-related, biological activity. ${ }^{56,57,58,59,60} \mathrm{At}$ "high" concentrations (30-70 $\mu \mathrm{g} \mathrm{O}_{3} / \mathrm{ml} \mathrm{O}_{2}$ ), it caused alterations and destruction of tissue structures. At medium concentrations (20-30 $\left.\mu \mathrm{g} \mathrm{O}_{3} / \mathrm{ml} \mathrm{O}_{2}\right)$ it appeared to affect the regulation of the immune system while at low concentrations $(<20$ $\mu \mathrm{g} \mathrm{O}_{3} / \mathrm{ml} \mathrm{O}_{2}$ ) it appeared to improve microcirculation. Experimental studies indicate that at adequate concentration and volumes, ozone has no mutagenic properties. ${ }^{61}$ Histological studies, performed on animal models, demonstrated that the intradiscal application of ozone at high concentrations $\left(30-40 \mu \mathrm{g} \mathrm{O}_{3} / \mathrm{ml} \mathrm{O}_{2}\right)$ produced degeneration of cytosol and cell shrinkage in the nucleus pulposus. ${ }^{24,62}$ Exposure of purified rheumatoid arthritis synovial fibroblast cells to ozone created an observable decreased production of proinflammatory factors TNF- $\alpha$, IL- $1 \mathrm{~b}$ and IL- $6 .{ }^{28}$ It could be supposed that the biochemical effect might have a leading or at least an early role in patient improvement while the volume reduction is a delayed and durable late effect.

In our opinion, intradiscal ozone offers a safe means of treating lumbar disc herniation without surgery. As stated above, it is possible that these patients would have gotten better spontaneously. It is recognized that the timing and indications for surgical discectomy are subjective. While intradiscal ozone injection may not be effective in all patients, the benefit-risk profile is attractive. Those patients that do not respond to the injection may still be treated with surgical discectomy. Intradiscal ozone injection is an extension of conservative management that may reduce the need for surgery and subsequent reoperations. Well-designed, randomized control trials are needed to confirm that intradiscal ozone injection is superior to traditional conservative care or a valid alternative to surgical treatment in select cases. Ozone chemonucleolysis is a simple, lowrisk procedure that bridges between existing conservative measures and surgical discectomy and is particularly useful in those patients without a clear-cut indication for surgical removal of the disc herniation.

\section{References}

1. Choy DS: Percutaneous laser disc decompression. J Clin Laser Med Surg 1995; 13:125-126. 
2. Martin BI, Mirza SK, Cornstock BA, Gray DT, Kreuter W, Deyo RA. Are lumbar spine reoperation rates falling with greater use of fusion surgery and new surgical technology. Spine 2007; 32(19): 2119-2126.

3. Weinstein JN, Tosteson TD, Lurie JD et al. Surgical vs non-operative treatment for lumbar disc herniation. The Spine Patients Outcomes Research Trial (SPORT): A randomized trial. JAMA 2006; 296: 2441-2450.

4. Weinstein JN, Tosteson TD, Lurie JD et al. Surgical vs non-operative treatment for lumbar disc herniation. The Spine Patients Outcomes Research Trial (SPORT): Observational cohort. JAMA 2006; 296: 2451-2459.

5. Atlas SJ, Keller RB, Wu YA, Deyo RA, Singer DE. Long-term outcomes of surgical and non-surgical management of sciatica secondary to a lumbar disc herniation: 10 year results from the Maine lumbar spine study. Spine 2005; 30(8): 927-935.

6. Findlay GF, Hall BI, Musa BS: A 10-year follow-up of the outcome of lumbar microdiscectomy. Spine 1998; 23:1168-71.

7. Gibson JNA, Grant IC, Waddell G: The Cochrane review of surgery for lumbar disc prolapse and degenerarive lumbar spondylosis. Spine 1999; 24:1820.

8. Moore AJ, Chilton JD, Uttley D: Long-term results of microlumbar discectomy. Br J Neurosurg 1994; 8:319-26.

9. Osterman H, Sund R, Seitsalo S, Keskimaki I: Risk of multiple reoperations after lumbar discectomy. A population based study. Spine 2003; 28(6): 621-627.

10. Yorimitsu E, Chiba K, Toyama Y, Hirabayashi K: Long-Term Outcomes of Standard Discectomy for Lumbar Disc Herniation. A Follow-Up Study of More Than 10 Years. Spine 2001; 26:652-657.

11. Asch HL, Lewis PJ, Moreland DB, Egnatchik JG, Yu J, Clabeaux DE, et al. Prospective multiple outcomes study of outpatient lumbar discectomy: should 7580\% success rates be the norm? J Neurosurg 2002; 96: 34-44.

12. Carragee EJ, Han MY, Yang B, Kim DH, Kraemer H, Billys J. Activity restrictions after posterior lumbar discectomy. A prospective study of outcomes in 152 cases with no postoperative restrictions. Spine 1999; 24(22): 2346-2351.

13. Loupasis GA, Stamos K, Katonis PG, Sapkas G, Korres S, Hartofilakidis G. Sevento 20 year outcome of lumbar discectomy. Spine 1999; 24(22): 2213-2317.

14. Hoffman RM, Wheeler KJ, Deyo RA. Surgery for herniated lumbar discs. A literature synthesis. J Gen Int Med 1993; 8: 487-496. 2115.

15. Fiume D, Sherkat S, Callovini GM, Parziale G, Gazzeri G: Treatment of the failed back surgery syndrome due to lumbosacral epidural fibrosis. Acta Neurochir (suppl) 1995; 64:116-118.

16. Fritsch EW, Heisel J, Rupp S: The failed back surgery syndrome: Reasons, intraoperative findings, and long-term results: A report of 182 operative treatments. Spine 1996; 21:626-33.

17. Ross JS, Robertson JT, Frederickson RC, Petrie JL, Obuchowski N, Modic MT et al: Association between peridural scar and recurrent radicular pain after lumbar discectomy: Magnetic resonance evaluation. ADCON-L European Study Group. Neurosurgery 1996; 38:855-61.

18. Friedly J, Chan L, Deyo R. Increases in lumbosacral injections in the Medicare population: 1994-2001. Spine 2007; (32(16): 1754-1760.

19. Carette S, Leclaire R, Marcoux S, Morin F, Blaise GA, St-Pierre A, et al. Epidural corticosteroid injections for sciatica due to herniated nucleus pulposus. NEJM 1997; 336(23): 1634-1640. 
20. Riew KN, Yin Y, Gilula L et al. The effect of nerve-root injections on the need for operative treatment of lumbar radicular pain. JBJS 2000; 82: 1589-1593.

21. Gerszten PC, Smuck M, Rathmell JP, Simopoulos TT, Bhagia SM, Mocek CK et al. Plasma disc decompression compared to fluoroscopy-guided transforaminal epidural steroid injections for symptomatic contained lumbar disc herniation: a prospective, randomized, controlled trial. J Neurosurg Spine 2010; 12(4): 357-371.

22. Soltes L, Mendichi R, Kogan G, Schiller J, Stankovska M, Arnhold J. Degradative Action of Reactive Oxygen Species on Hyaluronan. Biomacromolecules 2006; 7: 659-668.

23. Lenhert T, Naguib NN, Wutzler S, Nour-Eldin NE, Bauer RW, Kerl JM, et al. Analysis of disk volume before and after CT-guided intradiscal and periganglionic ozone-oxygen injection for the treatment of lumbar disc herniation. J Vasc Interv Radiol 2012; 23(11):1430-1436.

24. Iliakis E, Valadakis V, Vynios DH, Tsiganos CP, Agapitos E. Rationalization of the Activity of Medical Ozone on the Intervertebral Disc. A Histological and Biochemical Study. Rivista di Neuroradiologia 2001; 14(Suppl 1): 23-30.

25. Kim YS, Jeon BC, Kwon KY. Ozone chemonucleolysis on the lumbar intervertebral disc of the rabbit. J Korean Neurosurgical Soc 2003; 34(6): 570-574.

26. Tian JL, Zhang JS, Xiao YY, Liu JT, Yang B, Li JK, et al. Changes of CSF and spinal pathomorphology after high-concentration ozone injection into the subarachnoid space: an experimental study in pigs. Am J Neuroradiol 2007; 28: 1051-54.

27. Han HJ, Kim JY, Jang HY, Lee B, Yoon JH, Jang SK, et al. Fluoroscopic-guided intradiscal oxygen-ozone injection therapy for thoracolumbar intervertebral disc herniations in dogs. In vivo 2007: 21:609-614.

28. Chang JDS, Lu HS, Chang YF, Wang D. Ameliorative effect on ozone on cytokine production in mice injected with human rheumatoid arthritis synovial fibroblast cells. Rheumatol Int 2005; 26:141-151.

29. Fuccio C, Luongo C, Capodanno P, Giordano C, Scafuro MA, Siniscalco D et al. A single subcutaneous injection of ozone prevents allodynia and decreases the overexpression of pro-inflammatory caspases in the orbito-frontal corext of neuropathic mice. Eur J Pharacol 2009; 603: 42-9.

30. Gallucci M, Limbucci N, Zugaro L, Barile A, Stavroulis E, Ricci A, et al. Sciatica: Treatment with intradiscal and intraformainal injections of steroid and oxygen-ozone versus steroid only. Radiology 2007; 242: 907-913.

31. Buric J, Molino Lova R. Ozone chemonucleolysis in non-contained lumbar disc herniations: a pilot study with 12 months follow-up. Acta Neurochir Suppl. 2005;92:93-7.

32. Buric J. Ozone chemonucleolysis vs. microdiscectomy. Prospective controlled study with 18 months follow-up. Rivista Italiana di Ossigeno-Ozonoterapia 2005. 4: 49-54.

33. Paradiso R, Alexandre A. The different outcomes of patients with disc herniation treated either by microdiscectomy, or by intradiscal ozone injection. Acta Neurochir Suppl. 2005;92:139-42.

34. Muto M, Andreula $\mathrm{C}$, Leonardi $\mathrm{M}$. Treatment of herniated lumbar disc by intradiscal and intraforaminal oxygen-ozone (O2-O3) injection. J Neuroradiol. 2004 Jun;31(3):183-9.

35. Bonetti M, Fontana A, Cotticelli B, Volta GD, Guindani M, Leonardi M. Intraforaminal $\mathrm{O}(2)-\mathrm{O}(3)$ versus periradicular steroidal infiltrations in lower back 
pain: randomized controlled study. AJNR Am J Neuroradiol. 2005 May;26(5):9961000.

36. Alexandre A, Buric J, Paradiso R, Salgado H, Murga M, Coro L et al. Intradiscal injection of $\mathrm{O} 2-\mathrm{O} 3$ to treat lumbar disc herniations. Results at five years. Rivista Italiana di Ossigeno-Ozonoterapia 2002; 1: 165-169.

37. Andreula CF, Simonetti L, De Santis F, Agati R, Ricci R, Leonardi M. Minimally invasive oxygen-ozone therapy for lumbar disk herniation. AJNR 2003; May;24(5):996-1000.

38. Bonetti M, Fontana A, Albertini F. CT-guided oxygen-ozone treatment for first degree spondylolisthesis and spondylolysis. Acta Neurochir Suppl. 2005;92:87-92.

39. Ying WZ, Mei JC, Min WZ. Percutaneous treatment of lumbar disc herniation by oxygen-ozone injection. A clinical study of 322 cases. Rivista Italiana di OssigenoOzonoterapia 2005; 4:6-8.

40. Alexandre A, Coro L, Azuelos A, Buric J, Salgado H, Murga M et al. Intradiscal injection of oxygen-ozone gas mixture for the treatment of cervical disc herniations. Acta Neurochir Suppl. 2005; 92:79-82. 2341.

41. He XF, Xiao YY, Li YH, Lu W, Chien Y, Chien HW et al. Percutaneous intradiscal O2-O3 injection to treat cervical disc herniation. Revista di Neuroradiologia 2005; 18: 75-78.

42. Paoloni M, Sante L, Cacchio A, Apuzzo D, Marotta S, Razzano M et al. Intramuscular oxygen-ozone therapy in the treatment of acute back pain with lumbar disc herniation. Spine 2009; 34(13): 1337-1344.

43. Lo Guidice G, Valdi F, Gismondi M, Prosdocimo G, de Belvis V. Oxygen-ozone therapy for lumbar disk herniation. Am J Ophthalmology 2004: 138(1): 175-177.

44. Ginanneschi F, Cervelli C, Milani P, Rossi A. Ventral and dorsal root injury after oxygen-ozone therapy for lumbar disk herniation. Surg Neur 2006; 66: 619-621.

45. Devetag Chalaupka F, Caneve G, Mauri M, Zaiotti G. Thunderclap headache caused by minimally invasive medical procedures: Description of two cases. Headache 2007:47(2): 293-295.

46. Bo W, Longyi, C, Jian T, Guangfu H, Hailong F Weidong L. et al. A pyogenic discitis at $\mathrm{C} 3-\mathrm{C} 4$ with associated ventral epidural abscess involving $\mathrm{C} 1-\mathrm{C} 4$ after intradiscal ozone chemonucleolysis. Spine 2009; 34(8): E298-E304.

47. Gazzeri R, Galarza M, Neroni M, Esposito S, Alfieri A. Fulminating septicemia secondary to oxygen-ozone therapy in lumbar disc herniation. Case report. Spine 2007; 12(3): E121-E123.

48. Steppan J, Meaders T, Muto M, Murphy KJ. A metaanalysis of the effectiveness and safety of ozone treatments for herniated lumbar discs. JVIR 2010; 21(4): 534-548

49. Magalhaes FN, Dotta L, Sasse A, Teixeira MJ, Fonoff ET. Ozone therapy as a treatment for low back pain secondary to herniated disc: a systematic review and meta-analysis of randomized controlled trials. Pain Physician 2012; 15:115-E129.

50. Fraser RD, Sandhu A, Gogan WJ: Magnetic resonance imaging findings 10 years after treatment for lumbar disc herniation. Spine 1995; 20:710-714.

51. Wiesel SW, Tsourmas N, Feffer HL: A study of computer-associated tomography. The incidence of positive CAT scans in asymptomatic group of patients. Spine 1984; 9:549-51.

52. Takebayashi T, Cavanaugh JM, Ozakatay AC, Kallakuri S, Chen C: Effect of nucleus pulposus on the neural activity of dorsal root ganglion. Spine 2001; 26:940- 945. 
53. Yabuki S, Kikuchi S, Olmarker K, Myers RR: Acute effects of nucleus polposus on blood flow and endoneurial fluid pressure in rat dorsal root ganglia. Spine 1998; 23:2517-2523.

54. Chen C, Cavanaugh JM, Ozakaty AC, Kallakuri S, King DI: Effects of phospholipase A2 on lumbar nerve root structure and function. Spine 1997; 22:1057- 1064. 2455.

55. Olmarker K, Larsson K: Tumor necrosis factor $\alpha$ and nucleus pulposus induced nerve root injury. Spine 1998; 23:2538-2544.

56. Bocci V, Luzzi E, Canadeschi F, Paulesu L: Studies on the biological effects of ozone. Biotherapy 1994; 7:83-90.

57. Bocci V: Ozone as Janus: this controversial gas can be either toxic or medically useful. Mediators Inflamm 2004; 13:3-11.

58. Paulesu L, Luzzi E, Bocci V: Studies on the biological effects of ozone. Induction of tumor necrosis factor alfa on human leukocytes. Lymphokine e Cytokine Research 1991; 10:409-412.

59. Verrazzo G, Coppola L: Hyperbaric oxygen, oxygen-ozone therapy and rheologic parameters of blood in patients with peripheral occlusive arterial disease. Undersea Hyperbar Med 1995; 2:17-22.

60. Viebahn R (ed): The use of ozone in medicine. 2nd ed. Heilderberg: Karl F Hang Publishers, 1994.

61. Bocci V: [Compressione dei meccanismi di azione e possibilità terapeutiche], in Bocci V (ed): Ossigeno-Ozonoterapia. Casa editrice Ambrosiana 2000, pp 161-163.

62. Jucopilla N, Dall"Aglio R, Ferrarese C: Effetti dell"0203 sul disco intervertebrale di suino. Presented on the $1^{\circ}$ Congress of International Medical Ozone Society of Italy, Siena, November 2-4, 2000.

\section{Disclosures}

Josip Buric owns stock in and is on the advisory board of Minimus Spine. Luca Rigobello owns stock in Minimus Spine. David Hooper is the Founder \& CEO of Minimus Spine.

Copyright (C) 2014 ISASS - International Society for the Advancement of Spine Surgery. To see more or order reprints or permissions, see http://ijssurgery.com. 